\title{
Re-place-ing space in Libyan women's language learning and culture mapping
}

\author{
Melicent Jalova ${ }^{1, *}$ \\ ${ }^{1}$ Mindanao State University-Iligan Institute of Technology, Philippines
}

\begin{abstract}
Libya embarks on a new era in world relations where learning English has become a necessity. This study investigated how Libyan women managed to study abroad, found their place and learned a language despite the country's cultural subjection against women. It explored what motivated them to study English, how they felt about the learning environment, and the process of engaging themselves in intercultural exchange. Twelve female Libyan were subjects of this study. This study utilized a combination of the descriptive and analytical research designs. Since this is a qualitative study, the researcher used thematic analysis in analyzing and interpreting gathered data. It is founded in Milton Rokeach's Theory which says that each person has a highly organized system of beliefs, attitudes, and values, which guides behavior. Personal motivation and the desire to live through another culture without compromising its own concluded this study. The cultural construct that Libyan women can't decide and can't do a lot is unacceptable to these women who believe that they could play a very significant presence in the new government.
\end{abstract}

\section{Introduction}

Development encompasses many dimensions, levels, and processes. More so, various levels of development needed in any society necessitates a complex interweaving of strategies and programs to be able to effectively and efficiently deliver services to its citizens. Hence the dramatic effect of globalization today does not impede any country, culture or any person from learning a foreign language to help improve what it has in the past and present.

Libya, a country which suffers from political turmoil in the recent past is not exempted from this. After over four decades of oppression, Libyans are excited about living a good life and working to improve their educational system. And for a long time, they are now convinced of the great importance of improving the inadequate standard of English language in their country. As Libya embarks on a new era in world relations and under these circumstances, learning language, especially in English, has become a necessity and a key to success in business and study, and learning other culture. For more than a decade, Libya is one of the Arab countries where its government has invested heavily in English language learning by sending their teachers abroad to study.

\footnotetext{
${ }^{*}$ Corresponding author: melicent09@yahoo.com
} 
The goal on learning English is to enable Libya to catch up in the development of its economy and to promote international exchange [1].

The government's mandate to send scholars abroad encouraged many women to continue their studies in countries like UK, US, Canada, Asia and many other countries. According to a September 2013 report by the International Foundation for Electoral Systems (IFES) Libyan women are highly educated. The majority of college graduates in the country are women, with $77 \%$ pursuing higher education courses, compared to $63 \%$ of men [2].

It is inspiring to discover the number of Libyans who want to learn English; the number is large and it is increasing as Libya embarks on a new era in world relations and opening up to foreign investment. Under these circumstances, learning languages, especially English, is becoming a necessity and a key to success in business and study, let alone facilitating the search for a job, not only in academia, but also in government and private sectors.

\subsection{Embracing Language and Culture}

Language and culture are interrelated. First, language is the vehicle of culture. There is not any isolated language that can exist without culture. Language is rooted deeply in national culture, and like a mirror, it reflects a nation's beliefs, values, customs, and others Rivers, cited in Kadyskyzy, [3]. When one learns a language, one has to embrace its culture as well. One's ability to learn and understand a particular language depends on her deep understanding of culture otherwise this causes nonstandard linguistic error. (Krasner 1999, as cited in Peterson and Coltrane, 2003) [4] stated that linguists and anthropologists have identified that forms and uses of a particular language reflect the cultural value of society in which that language is spoken.

\subsection{Understanding Language and Culture in a Lexical Level}

One can learn much about the connection between language and culture by studying the availability and use of words in language communities. Sapir as cited by Corbett [5] commented that vocabulary is a very sensitive index of the culture of a group of people. Even at the lexical or vocabulary level, one can often get a sense of how individuals perceive themselves as members of society and members of specific cultures. The differences in word usage between languages can have serious implications for those who attempt to converse in a language not their own if they assume the same words in both languages carry equivalent meanings [6].

\subsection{Female Libyan English Teachers}

Libyan English teachers are the fountain of knowledge among Libyan students. They are the source of ideas, skills and knowledge of learners. But often, female teachers are so limited in sharing their expertise because of the cultural constrains of the country. They have issues and concerns that are not acceptable in the society. This wall of culture restricts them to use appropriate techniques in language teaching and limit their ability to teach the language.

Since people do not learn a language in isolation, they engage in numerous activities and become active members to experience, observe, understand, explore, participate, meet and use the language. Wilson, [7] said that what a person learns and how they make sense of that knowledge depends on where and when they are learning, such as the social context. 
Libyan teachers going abroad to study English become English Libyan teachers in a particular social context, using a particular kind of knowledge at a particular time, therefore, their practices have become socially constructed. These practices can be seen as constructed from their cultural background, views on learning, and the kind of education they have received.

\section{General Objectives}

To find out what motivated Libyan women to study English abroad, how they felt about the learning environment, and the process of engaging themselves in intercultural exchange. Specific Objectives:

1. To find out how learning the English language abroad embody that cultural reality among Libyan women when they teach in Libya

2. To determine how Libyan women negotiate their cultural status in learning and teaching English

3. To determine the attitude of Libyan women towards learning English

3 Study Framework

How people behave-- how they greet one another, what and how they eat, what their manners among others - is motivated or shaped by their dominant attitudes, values, and beliefs. This idea is founded in Milton Rokeach's Theory which says that each person has a highly organized system of beliefs, attitudes, and values, which guides behavior.

An excellent way to illustrate the relationship among behavior, beliefs, attitudes and values is by making an analogy between culture and an iceberg, as suggested by Edward Hall [8] following Sigmund Freud's analogy of the unconscious mind with an iceberg. The tip of the iceberg, which he termed as the external culture, is really the smallest part. This refers to the explicit and conscious behavioral aspects such as language or verbal communication, customs, and typical food or dress. These can be acquired through observation, education or training. The largest part of culture is inside an individual's head and unconscious - beneath the water level of awareness. This part, which he called the internal culture, is what motivates behavior. It includes beliefs which are learned implicitly or unconsciously through interaction with others within a particular culture. They include likes or dislikes (attitudes) and things that are important to us which we want or desire (values). The largest and the most hidden part of any culture includes basic values, ways of thinking and perceiving, and non-verbal communication. They are implicitly learned before adolescence and are difficult to change.

\section{Methodology}

This study utilized a combination of the descriptive and analytical research designs. Since this is a qualitative study, the researcher used thematic analysis in analyzing and interpreting gathered data.

Participants. Twelve Libyan women participated in the study. Two studied at University of Malaysia, four studied at Essex University in UK, four at University of Manchester, one at University of Birmingham, and one from University of Glasgow, Scotland. Seven have Masteral degrees; while five had finished their Doctoral degrees.

Four of them are teaching at Sirte University, four in Tripoli University, and the other four are teaching at Gariounis University in Bengazi, Libya.

Administration. The researcher traveled in Tripoli and Bengazi to conduct the interview. Focus interview and FGD were used to get the information needed. These were done in a field setting, more specifically in the campus where the teachers were based. 
A key informant was tapped to help and provide the necessary contact of the participants.

Meanwhile, the participants from Sirte University were interviewed in a more relaxed setting because the researcher also taught in the same university.

Method. The researcher formulated a set of guide questions which formed the core questions that was asked. The questions reflected the specific concepts needed to achieve the answers of research questions as well as to provide information on certain aspects of the study.

Data Analysis. To analyze the gathered data, the researcher separately coded the responses of the participants. Commonalities and peculiarities of the responses were noted.

Based on the framework of the study and the data collected, analyses and conclusions were drawn using the thematic approach. The themes used were: Libyan culture, other culture, negotiation and language learning.

\section{Findings and Discussion}

Motivation to deeply learn the language is the key factor in learning a language. Littlewood [9] explained that motivation is the crucial force which determines whether a learner embarks on a task at all, how much energy he devotes to it, and how long he perseveres.

Just like any other scholars who are thirsty to gain more knowledge and are passionate to learn and teach English, Libyan women are also equally empowered to do so. After a tedious application in the Ministry of Education in Libya, being accepted at the universities abroad, and a grueling argument who among in the family members can join her (husband if she's married; father or brother if she's single), at her desired country of choice, she travels and enjoy her scholarship. As one discussant quipped, "It took me a long time to study because no one could come with me. I had to wait for my brother to finish his studies so he could come with me. There is no way I could go and study without my brother or father. Sadly, others could not study abroad because no one could go with them and stay for two or more years. Finding a husband to accompany to study (sometimes) was the right thing to do."

The country's cultural subjection against women was the biggest challenge among the participants. But the motivation to learn and be immersed in an English speaking country was the biggest inspiration to push the goal. Different researches have been investigated on the effects of attitudes on motivation and proficiency in a large number of studies. Clearly, the women are motivated by a mixture of integrative and instrumental motivation, that is; the former is learning the language in order to communicate more satisfactorily and to gain closer contact to people and their culture and the latter was to further another goal.

Individual's drive to achieve a goal, curiosity of the new country to live, be successful, desire for new experience and be a true scholar are the factors that motivated them to study abroad. "I wanted to improve my English and teach English to Libyans, that's my goal." I wanted to be fluent and develop confidence when I speak English especially with my students, and "I wanted to feel how it was to speak with native speakers and speak with confidence when I was with them" are among the goals of Libyan women that drive them to get a Master's degree or $\mathrm{PhD}$ in another country.

Given the favorable factors that motivate them to study English language there are also risks in learning the language. Littlewood [9] stressed that there is a close link between the way a person speaks and the way the person perceives her identity and the world. He further stressed that when one tries to adopt new speech patterns, at some extent, one is giving up markers of her own identity in order to adopt those of another cultural group. In some respects, one is accepting another culture's way of perceiving the world. If she is 
agreeable to this process, it can enrich and liberate her. If not, it can be a source of resentment and insecurity.

But Libyan women are very strongly connected to their roots. They very well define and assert their identity in learning English. "I studied ELT without compromising my culture or anything. "Yes, it was good to meet new friends, in a new and different world, but I always carry my roots, my religion ALWAYS. There's no compromise." "I was there to study only, I get to learn their culture, the importance of studying language and culture but at the end of the day, I am still a Libyan in words, in thoughts, and in deeds."

It is worthy to note how Libyans could learn the English language without really embracing the personality of the proponent culture. If Libyan women remain dogged in their ethnocentric stance and are reluctant in acculturating or assimilating themselves into a given culture, their learning of English maybe a difficult process. From the perspective of a native speaker their English may be badly spoken and hardly understood.

On the other hand, their intense motivation to learn a language transformed their learning process into a willful determination to surpass all odds.

The researcher believes that despite the process of getting acculturated into Englishspeaking cultures, Libyan women have developed a sense of cultural resilience or the ability to keep their core value of keeping their culture intact. Based on the participant's disclosure, "It's there. Wherever you go, you keep your own culture with you especially us women, it's precious in Islam,"

Although Libya's image is very fragile at this point, Libyan women's love of their country, knowing who they are is very evident. It cannot be snatched by external forces or agencies. It is deeply ingrained. Also, the perennial psychological link to one's country is wrought by human instinct to always go back to one's origin; in a way, "coming home."

Moreover, Islam is found to be a significant factor in the participant's emotional and deep sentiment about her being in other country. The teachings of Quor'an along with their family are the significant shaper of their children's mindset, also paved the way for the participant's "high context" mindset [8] - a very strictly defined orientation- characterized by adherence to the teachings of Allah. Everything outside of Quor'an, in their belief, is not worth their while when it comes to the realm of faith and values.

The Role of Libyan language instructors in teaching English

The role played by the female instructors is negotiated in certain ways that they are always "careful" when they teach the language without compromising their culture. Students' embarrassment may rise when conflicting issues in their culture get in the way. It emerged during the focus group discussion that the activities like role play, or even reporting are very difficult to do. "There are boys who would not recite or report in class if the girls are there. "We have to let the girls go home and then the boys would have their oral report." Or at times, "girls would not participate if there are boys." There was one instance that one female student stopped attending classes because the subject required to speak in front of the class and the teacher was called."

Being Libyan themselves, they understand the feelings of students. "That is why we give some subjects to foreigners because they know how to deal with students without embarrassing and offending them. Examples of these subjects are Literature and Spoken English classes where students are required to share, talk and do group activities. As Libyans ourselves, we cannot impose those activities to students."

There are profound consequences when an L2 learner participates in an L1 culture [5]. Since language learning involves oral activities to achieve fluency, one has to participate in class activities. But if a certain culture inhibits some students to participate because of the presence of the opposite gender then negotiations have to be made at certain extent. The teacher has to adjust her activities between the interests of the learners and the demands of the culture [5]. 
Bonvillain, [10] says that language fulfills diverse functions either separately or simultaneously. No matter how universal these functions of language are, methods of achieving them differ both in linguistic form and cultural style.

For a female Libyan teacher, teaching the language is teaching the culture itself. "When I open my mouth in English, am I not teaching foreign culture?" one participant asked. According to Stern, [11] a language teacher is the teacher of culture. No matter how and what strategies, techniques, and motivations she does in the classroom in teaching the language, she embodies the culture of other countries. She just have to adjust her language and decide what class activities that best suit the need of the learners without offending their own culture.

In Kramsch [12] notes of E. Sapir's, 'The Relationship of Language and Culture', he said that language is a guide to "social reality." It strongly affected our thinking about social problem and processes.

Libyan women whose ropes have loosened to educate themselves abroad have something in them to share to the world. That is -- without loosely giving in to the target language culture, they are able to survive learning the language abroad, teaching the language at home, and holding on to a positive attitude of elevating the standards of English language teaching in Libya.

\section{Conclusion}

It is inspiring to discover the number of Libyans who want to learn English; the number is large and it is increasing as Libya embarks on a new era in world relations and opening up to foreign investment. Under these circumstances, learning languages, especially English, is becoming a necessity and a key to success in business and study, let alone facilitating the search for a job whether in academia, government or private sector.

Libyan women are go-getters waiting for opportunities to come. The cultural construct that they can't decide and can't do a lot is unacceptable to these women who believe that they could play a very significant presence in the new government.

It takes only one good reason to learn English. Libyans have many reasons and a clear awareness of the significance of English. These female scholars who continue to pursue their dreams including their determination to secure their place in shaping Libya's future through their students are called for. It is up to the new government to make sure that the level of education in Libya now is at par with the very best in the world thus ensuring a secure and peaceful environment, where children and students could come and learn. It is also the government's responsibility to ensure that all the schools will meet a certain criterion so that students are equipped with the modern knowledge along with a better educational system to face the world head-on.

\section{References}

1. M. Sinosi, Linguistic and textual analysis of classroom English interaction at Altahadi University. (2010)

2. J. Sarhan, Libyan women struggle to join the workforce (2014)

3. A. Kadyskyzy, SINO-US E.T, 10, 23-31 (2013)

4. E. Peterson and B. Coltrane, ERIC D. (2003)

5. J. Corbett, An intercultural approach to English language teaching (2007).

6. P. N. Chrosniak, Encyclopedia of Anthropology (2005)

7. K. Wilson, JOCRAL, 29, 166-179 (1999)

8. E.T. Hall. The silent language (1998)

9. W. Littlewood, Foreign and second language learning (1998) 
10. N. Bonvillain, Language, culture and communication. The meaning of messages (1998)

11. H.H. Stern. Fundamental concepts of language teaching (1983)

12. C. Kramsch, Language and culture (1998) 